\title{
Quality of life of children with hearing loss in special and mainstream education: A longitudinal study
}

\author{
Tirza F.K. van der Straaten ${ }^{\mathrm{a}}$, Carolien Rieffe ${ }^{\mathrm{b}, \mathrm{c}, \mathrm{d}}$, Wim Soede ${ }^{\mathrm{a}}$, Anouk P. Netten ${ }^{\mathrm{a}}$, Evelien Dirks ${ }^{\mathrm{c}}$, \\ Anne Marie Oudesluys-Murphy ${ }^{\mathrm{e}}$, Friedo W. Dekker ${ }^{\mathrm{f}}$, Stefan Böhringer ${ }^{\mathrm{g}}$, Johan H.M. Frijns ${ }^{\mathrm{a}, \mathrm{h}, *}$, on \\ behalf of the DECIBEL Collaborative study group \\ ${ }^{a}$ Department of Otorhinolaryngology and Head \& Neck Surgery, Leiden University Medical Center, P.O. Box 9600, 2300 RC, Leiden, the Netherlands \\ ${ }^{\mathrm{b}}$ Department of Developmental Psychology, Leiden University, P.O. Box 9555, 2300 RB, Leiden, the Netherlands \\ ${ }^{\mathrm{c}}$ Dutch Foundation for the Deaf and Hard of Hearing Child, Lutmastraat 167, 1073 GX, Amsterdam, the Netherlands \\ ${ }^{\mathrm{d}}$ Department of Psychology and Human Development, University College London, London WC1H OAA, United Kingdom \\ ${ }^{\mathrm{e}}$ Willem-Alexander Children's Hospital, Department of Social Pediatrics, Leiden University Medical Center, P.O. Box 9600,2300 RC, Leiden, the Netherlands \\ ${ }^{\mathrm{f}}$ Department of Clinical Epidemiology, Leiden University Medical Center, P.O. Box 9600, 2300 RC, Leiden, the Netherlands \\ ${ }^{g}$ Department of Medical Statistics, Leiden University Medical Center, P.O. Box 9600, 2300 RC, Leiden, the Netherlands \\ ${ }^{\mathrm{h}}$ Leiden Institute for Brain and Cognition, Leiden University Medical Center, P.O. Box 9600, 2300 RC, Leiden, the Netherlands
}

\section{A R T I C L E I N F O}

\section{Keywords:}

Hearing loss

Children

Cochlear implants

Hearing aids

Quality of life

Longitudinal

Language

Mainstream education

Special education

\begin{abstract}
A B S T R A C T
Objectives: To compare the quality of life (QoL) of children with hearing loss (HL) and children with normal hearing $(\mathrm{NH})$ and to examine how the QoL of children with HL changes over time, considering language skills, type of hearing device, degree of HL, and type of education.

Methods and materials: This longitudinal study included 62 children with HL and their parents. Developmental outcome data were collected at two time points, when the mean ages of the children were 4 and 11 years. The Pediatric Quality of Life (PedsQL ${ }^{\mathrm{TM}}$ ) questionnaire, which includes assessments of Physical, Emotional, Social, and School functioning, was completed by parents at both time points and by the children with HL at the second time point. Receptive and expressive language skills at 4 years were assessed by the Reynell Developmental Language Scale. Results were compared with a Dutch normative sample.

Results: The QoL of children with HL was similar to that of children with NH at both time points on two of the four QoL scales, Emotional and Physical functioning. On the other two scales, Social and School functioning, children with HL who attended special education and children who switched to mainstream education showed lower scores than children with HL who were consistently in mainstream education and lower scores than children with NH. The School QoL of children with HL decreased over time, as did the School QoL of children with NH. Social QoL of children with cochlear implants decreased over time, but this was not the case in children with hearing aids. Language skills and the degree of HL did not clinically improve the QoL over time of preschool children with HL.

Conclusions: The QoL of children with HL in mainstream education and the Physical and Emotional QoL of all children with HL were satisfactory. It is essential to develop specific guidance regarding school activities for children with HL in special education and for children with HL who switch to mainstream education in order to increase their social QoL.
\end{abstract}

\section{Introduction}

Hearing loss (HL) greater than $25 \mathrm{~dB} \mathrm{HL}$ is a serious condition that affects 1-1.7:1000 infants worldwide at birth and this number increases with age due to progressive or late onset hearing loss [1-3]. Children who have been identified with permanent childhood hearing impairment which require auditory amplification must cope with their HL in everyday situations. They experience language and communication problems that are consequences of their diminished auditory input [4-6]. In noisy environments, such as classrooms or school playgrounds, they regularly misperceive crucial information [7-10]. The misunderstanding and/or misinterpreting of social situations can lead

\footnotetext{
* Corresponding author. P.O. Box 9600, Leiden, the Netherlands.

E-mail address: J.H.M.Frijns@lumc.nl (J.H.M. Frijns).
} 
to feelings of exclusion and eventually to social and emotional difficulties [4,11-13]. Meta-analyses show that HL is associated with a lower quality of life (QoL) for social interactions and school activities $[14,15]$. Although factors such as hearing devices $[14,16,17]$ and better language skills $[12,18,19]$ contribute positively to the development and QoL of children with HL, these studies are cross-sectional, which prevents us from drawing conclusions about the causality of these relationships. Therefore, the present longitudinal study investigated the extent to which QoL of children with HL changed over time and whether language ability, type of hearing device, degree of HL, and type of education were associated with changes in QoL of these children.

Health-related QoL, which we refer to as QoL, encompasses the physical and psychosocial aspects of an individual's perception of their position in life [20]. QoL is an important outcome measure that is widely used for clinical and research purposes to assess the impact of acute and chronic diseases, to compare affected individuals with healthy individuals, and to measure progress after treatment. It is known that QoL of children with HL increases after receiving auditory rehabilitation alongside their hearing device such as a hearing aid (HA) or cochlear implant (CI) $[14,16,17]$. However, there appears to be a lack of consistency within the literature regarding the comparison of QoL of children with and without HL. Some studies reported no difference $[21,22]$ and a number of studies showed that children with HL had a lower QoL compared to the children without HL [23-25]. When considering the different domains of QoL, the outcomes of a metaanalysis showed that children with HL had lower general QoL in terms of school and social domains than their peers with normal hearing (NH), although children with and without HL did not differ in physical and emotional domains [14]. The lower QoL with regard to school and social domains is often assumed to be related to the diminished auditory input received by children with HL. However, various other risk and protective factors affecting the QoL of individuals with HL have been identified.

Many studies emphasize the importance of language for the development of children with HL $[12,18,19]$. Language delays are relatively common in children with HL and affect their communication, academic outcomes, and social-emotional functioning since they face more difficulties in expressing themselves and understanding others $[4,5,11,18,26,27]$. In addition, the type of educational setting is reported to be related to the QoL of children with HL. Children in special education report a lower QoL than children with and without HL in mainstream settings. This is associated with IQ level, additional disabilities, degree of HL, and communication abilities [25,28,29]. Inclusive educational settings have made it possible to include children with HL without additional severe disabilities and who have adequate speech and language skills into mainstream schools with or without extra support [30-34]. No studies to date have examined whether switching from special to mainstream education has an impact on the QoL of children with HL in comparison to children with HL who remain in special or mainstream education.

To the best of our knowledge, this nationwide study is the first to examine longitudinal changes of QoL outcomes of children with HL. Longitudinal studies can identify causal relationships and define developmental trends between groups. Data of this study were collected at two time points, when the mean ages of the children with HL were 4 and 11 years. These time points captured the beginning and end of their primary school years, allowing us to obtain an impression of the development of QoL of school-aged children with HL.

First, we compared the QoL of children with HL with the QoL of a normative group of Dutch children with NH [14]. Second, we examined changes in the QoL of children with HL over time. Given the lack of research in children with HL, we based our expectations on research in children with $\mathrm{NH}$ and expected a decrease of QoL over time as life becomes more challenging with age $[35,36]$. Third, we aimed to identify the risk and protective factors associated with changes in the QoL over time of children with HL. Based on existing literature, we expected that higher language skills and attending mainstream education would have a positive effect on the QoL $[4,6,12,25,28,29]$. This study also considered the QoL of a novel group of children with HL, namely those who switched from special to mainstream education and compared them with those who remained in their educational setting between the ages of 4 and 11 years. Given the inconclusive results in terms of the level of QoL of children with either HAs or CIs $[37,38]$ and the degree of HL $[39,40]$, no specific expectations could be formulated in this respect.

\section{Methods and materials}

\subsection{Procedure}

This longitudinal study is part of the DECIBEL study (Developmental Evaluation of Children: Impact and Benefits of Early hearing screening strategies Leiden). In this nationwide study, the parents of 204 children with HL aged 2-6 years agreed to participate in the first measurement, which took place from 2008 to 2010 (Time 1). After providing informed consent, the parents completed a QoL questionnaire (at this time children were too young to complete a self-report) and a general background questionnaire (characteristics of children e.g., mode of communication). With the parents' permission, the children's audiological and medical records were reviewed to collect background information and information on language skills. These outcomes were published previously $[1,12,41]$.

All 204 children who participated in the first study were invited to participate in a follow-up study 7 years later, just before they went to secondary school (Time 2). At this time point, 62 children with HL and their parents provided informed consent (a response rate of $30.4 \%$ ). The main reasons for not participating at Time 2 were; additional nonauditory disabilities $(n=6)$, already participating in other research or medical/audiological assessments $(n=2)$, and the burden of the study along with exams during the last year of primary school together with switching to secondary school $(n=2)$. The remaining 132 children did not provide a reason for non-participation. Children were visited at home between 2015 and 2016 when they were 10-13 years old. At this age, they reported their QoL via a self-report questionnaire and completed a language task. The parents also completed questionnaires about their child's QoL and provided additional background information (e.g., preferred communication mode). Audiological and medical records were reviewed again. Ethical approval for this study was obtained from the Medical Ethics Committee of Leiden University Medical Center (LUMC, ref. P14.270 20-01-2015).

\subsection{Participants of this study compared to the non-responders at time 2}

The final study group consisted of 62 children with bilateral HL (Table 1). The 62 children with HL who participated at Time 2 and the 142 children who did not participate at Time 2 were not significantly different in terms of sex, degree of HL, or type of hearing device. The level of education of the mother, the Total QoL, and the Physical QoL of the child at Time 1 was higher in the follow-up group than in the group that participated only at Time 1 (for further information please see the supplementary table).

\subsection{Materials}

\subsubsection{Quality of life}

The Pediatric Quality of Life Inventory (PedsQL ${ }^{\mathrm{TM}}$ ) [42,43] incorporates four domains: Physical functioning (e.g. "I have problems with running"; 8 items), Emotional functioning ("I feel sad"), Social functioning ("Other children are teasing me"), and School functioning ("It is difficult to pay attention in class") (the last 3 domains have 5 items each for a total of 15 items). Each of the 23 items are scored on a 5-point Likert scale: never, 0 points; almost never, 1 point; sometimes, 2 
Table 1

Demographic characteristics of the children with hearing loss in this study $(n=62)$.

\begin{tabular}{|c|c|c|}
\hline & Time 1 & Time 2 \\
\hline \multicolumn{3}{|l|}{ Age at time of assessment } \\
\hline Mean, years; months (SD) & $4 ; 5(0 ; 9)$ & $11 ; 10(0 ; 10)$ \\
\hline Range, years; months & $2 ; 6-6 ; 0$ & $10 ; 5-13 ; 6$ \\
\hline \multicolumn{3}{|l|}{ Sex, $n(\%)$} \\
\hline Male & $40(64.5)$ & \\
\hline \multicolumn{3}{|l|}{ Hearing amplification type, $n(\%)^{*}$} \\
\hline Hearing aid & $50(80.6)$ & $46(74.2)$ \\
\hline Cochlear implant & $11(17.7)$ & $16(25.8)$ \\
\hline Bone-anchored hearing aid & $1(1.6)$ & 0 \\
\hline \multicolumn{3}{|l|}{ Degree of hearing loss, $n(\%)^{* *}$} \\
\hline$<40 \mathrm{~dB}$ (mild) & $7(11.3)$ & $10(16.1)$ \\
\hline $41-60 \mathrm{~dB}$ (moderate) & $28(45.2)$ & $19(30.6)$ \\
\hline $61-80 \mathrm{~dB}$ (severe) & $14(22.6)$ & $14(22.6)$ \\
\hline$>80 \mathrm{~dB}$ (profound) & $13(21.0)$ & $19(30.6)$ \\
\hline Mean age at detection, months (SD) & $13.40(16.2)$ & \\
\hline Age range at detection, months & $0-50$ & \\
\hline Mean age at amplification, months (SD) & $21.44(15.0)$ & \\
\hline Age range at amplification, months & $2-55$ & \\
\hline \multicolumn{3}{|l|}{ Education, $n(\%)^{* * *}$} \\
\hline Mainstream & $20(32.3)$ & $47(75.8)$ \\
\hline Special & $42(67.7)$ & $15(24.2)$ \\
\hline \multicolumn{3}{|l|}{ Preferred mode of communication, $n(\%)$} \\
\hline Oral language only & $32(51.5)$ & $55(88.7)$ \\
\hline Spoken and sign-supported & $18(29)$ & $7(11.3)$ \\
\hline Spoken, sign, and sign-supported & $3(4.8)$ & \\
\hline Sign language only & $2(3.2)$ & \\
\hline Sign-supported & $2(3.2)$ & \\
\hline Sign and sign-supported & $1(1.6)$ & \\
\hline Missing & $4(6.5)$ & \\
\hline \multicolumn{3}{|l|}{ Receptive Language Skills, $n(\%)$} \\
\hline One standard deviation below average $<85$ & $28(52.8)$ & $22(35.5)$ \\
\hline Average $85-100$ & $14(26.4)$ & $18(29.0)$ \\
\hline Average $>100$ & $11(20.8)$ & $22(35.5)$ \\
\hline \multicolumn{3}{|l|}{ Expressive Language Skills, $n(\%)$} \\
\hline One standard deviation below average $<85$ & $23(37.1)$ & $16(25.8)$ \\
\hline Average 85-100 & $14(22.6)$ & $23(37.1)$ \\
\hline Average $>100$ & $11(17.7)$ & $23(37.1)$ \\
\hline \multicolumn{3}{|l|}{ Maternal education, $n(\%)$} \\
\hline Primary/lower general secondary education & $4(6.4)$ & \\
\hline Secondary vocational education & $20(32.3)$ & \\
\hline Higher general secondary education & $6(9.7)$ & \\
\hline College/university & $32(51.6)$ & \\
\hline
\end{tabular}

Time 1: 2008 to 2010; Time 2: 2015 to 2016. One child had a diagnosis of autism spectrum disorder, and another had a developmental delay with severe physical impairment. *After Time 1, five children received cochlear implants, and one child used a hearing aid instead of a bone-anchored hearing aid. **The degree of hearing loss was calculated by averaging unaided hearing thresholds at 500, 1000, 2000, and $4000 \mathrm{~Hz}$. Between Time 1 and 2, three children changed from having moderate to having mild hearing loss because their middle ear problems resolved spontaneously or after surgery. Six children deteriorated from having moderate to having profound hearing loss from Time 1 to Time 2 due to progressive hearing loss. $* * * 29 \%$ of the children with HL attended mainstream education at both time points, and $24.2 \%$ attended special education at both time points. Between 4 and 11 years of age, $47.8 \%$ of the children switched from special to mainstream education due to adequate speech and language skills. Of all the children in mainstream education, $44.7 \%$ received remedial teaching during school hours and $12.7 \%$ still used speech therapy at time 2 .

points; often, 3 points; almost always, 4 points. Each answer is reversescored and rescaled to a 0 to 100 scale, where higher scores indicate better QoL. The parent questionnaires are parallel versions of the children's self-reported questionnaires, with differences in the use of age-appropriate language and first- or third-person tense. In this study, the questionnaire was completed by parents at both time points and by children with HL at the second time point. The mean QoL as reported by the parents at Time 1 and by the children with HL themselves at Time 2 were compared with the available QoL outcomes of Dutch children with $\mathrm{NH}$ within the same age range (mean differences presented in Table 2)

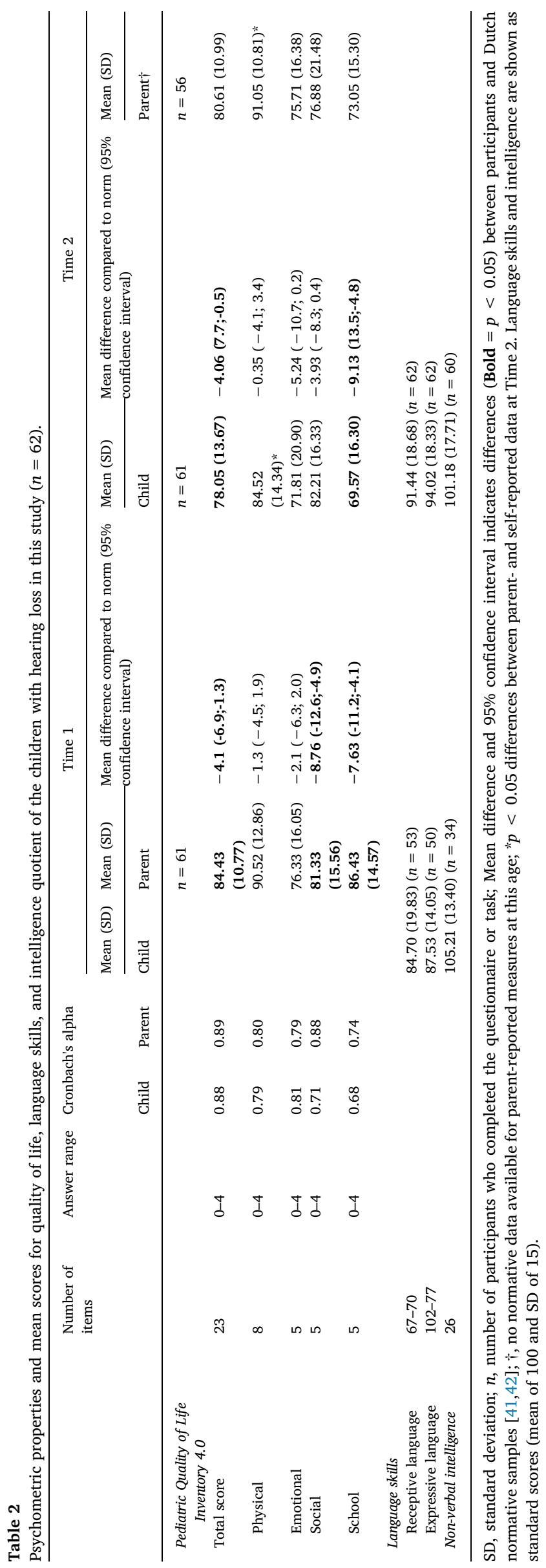


Table 3

Changes of quality of life over time of children with hearing loss $(n=62)$ analyzed with linear mixed models.

\begin{tabular}{|c|c|c|c|c|}
\hline & \multicolumn{2}{|l|}{$\begin{array}{l}\text { Time } \\
\text { Uncorrected }\end{array}$} & \multicolumn{2}{|c|}{$\begin{array}{l}\text { Time } \\
\text { Corrected for sex and age at Time } \\
1\end{array}$} \\
\hline & Coefficients & $\begin{array}{l}\text { 95\% Confidence } \\
\text { interval }\end{array}$ & Coefficients & $\begin{array}{l}\text { 95\% Confidence } \\
\text { interval }\end{array}$ \\
\hline Total QoL & $-3.59 *$ & {$[-6.47,-0.70]$} & $-3.86^{* *}$ & {$[-6.74,-0.98]$} \\
\hline Physical QoL & 0.60 & {$[-2.60,3.80]$} & 0.39 & {$[-2.82,3.60]$} \\
\hline Emotional QoL & 0.10 & {$[-5.21,5.40]$} & -0.10 & {$[-5.47,5.27]$} \\
\hline Social QoL & -4.19 & {$[-9.54,1.16]$} & -4.64 & {$[-9.98,0.69]$} \\
\hline School QoL & $-13.49 * * *$ & {$[-18.18,-8.80]$} & $-13.73^{* * *}$ & {$[-18.44,-9.02]$} \\
\hline
\end{tabular}

Bold $* p \leq 0.05, * * p \leq 0.01, * * * p \leq 0.001$; Time: $0=$ Time $1,1=$ Time 2; QoL, quality of life.

[44,45]. A clinically significant difference was considered when the reported QoL was exceeded by the absolute value of 4 [14]. Both the English and Dutch versions of the questionnaire have shown good reliability and validity [44-46].

\subsubsection{Language skills}

Both receptive and expressive language skills were measured with age-appropriate tests. The Dutch version of the Reynell Developmental Language Scale was administered at Time 1 (appropriate for children aged 1;2-6;3 years and language levels of 55-145) [47] and the Clinical Evaluation of Language Fundamentals - Fourth Edition (CELF-4 ${ }^{{ }^{N L}}$ ) at Time 2 (appropriate for children aged 5-15 years and language levels of 40-160) $[48,49]$. Receptive language abilities were assessed with a verbal comprehension scale and expressive language abilities were assessed with word and sentence development scales. All language outcomes are standardized to norm scores according to age, using quotients in which the population mean for hearing children is 100 with a minimal clinical important difference of one standard deviation (SD) of 15 (e.g., 85 is below average and indicates language difficulties).

\subsubsection{Intelligence}

At Time 1, the nonverbal intelligence quotient (IQ) was derived from the child's medical files (either the Snijders-Oomen nonverbal intelligence tests or the Bayley Scales of Infant and Toddler Development-III) [50]. Nonverbal IQ at Time 2 was assessed at home using the block design and picture concepts components of the Wechsler Intelligence Scale for Children-Third Edition (WISC-III) [51,52].

\subsection{Statistical analysis}

Statistical analysis was performed on the final study group consisting of 62 children with bilateral HL. To compare the QoL of children with HL with Dutch normative data, summary independent sample $t$ tests were performed for the Total QoL score and for each domain separately $[44,45]$. To compare self-reported QoL with parent-reported QoL at Time 2, we used a dependent sample $t$-test. To evaluate whether QoL of children with HL had changed after 7 years, linear mixed models were used. Because we were interested in the development of QoL over time, parent-reported data of the final 62 children with HL were used as they reported the QoL of their children with HL at both time points. To control for confounders, sex and age at Time 1 were added as fixed effects in these linear mixed models [35]. Next, we examined the effects of the following factors on changes in the QoL over time: language skills at Time 1, type of hearing device, degree of HL, and educational settings (mainstream education, special education, or switched from special to mainstream education between the two time points). Accordingly, each variable was sequentially added (first main effect and second interaction effect with Time). In addition to sex and age at Time
1, level of IQ was added as a confounder to the model with educational settings. Due to the large number of missing IQ scores at Time 1, the IQscore at Time 2 was used in the analyses (Pearson's correlation between IQ Time 1 and Time $2=0.385, p=0.027$ ) [53]. All linear mixed models contained a single random effect for each subject and fixed effects for the independent variables. Statistical analyses were performed using the IBM SPSS Statistics 23.0 software package.

\subsubsection{Missing data}

In our final study sample of 62 children, receptive language, expressive language, and IQ scores at Time 1 were missing for 9, 12, and 28 children with HL, respectively (Table 2). At Time 2, one child was unable to complete the QoL-questionnaire and IQ measure due to her additional non-auditory disability, one child lost her focus while completing the IQ measure at the end of the testing session, and six parentreported QoL outcome questionnaires were incomplete. The pattern of missing data was examined using Little's MCAR test $\left(\chi^{2}=483.47\right.$, $\mathrm{DF}=529, p=0.92)$, which indicated that the data were missing at random. When conducting standard analyses, such as independent $t$ tests, incomplete cases will automatically be excluded [54]. This can introduce bias and lower statistical power if these participants were excluded from the analyses. This type of missing data can be reconstructed using multiple imputations [54-56]. We used 10 imputations to create good estimates of the missing data [56]. The imputations were based on the child's age at Time 1 and Time 2, language skills, IQ, sex, educational status of the parents, and QoL outcomes. Ten imputations were performed, and the pooled results are reported in Tables 3 and 4 [56]. There were no differences between outcomes with the original data and the imputed data.

\section{Results}

The outcomes are reported in order of the three aims of this study.

\subsection{Comparison of the QoL of children with HL versus normative QoL data from Dutch children with $\mathrm{NH}$}

The psychometric properties and mean QoL results of the final study sample of 62 children with HL are shown in Table 2. At Time 1, parents reported a clinically lower Total QoL for children with HL compared to the parent-reported normative data from Dutch children with $\mathrm{NH}$. When considering the different subscales reported by parents, QoL scores among children with HL were clinically lower compared to children with $\mathrm{NH}$ in the Social and School domains at Time 1. At Time 2 , the children with HL self-reported a clinically lower Total QoL compared to the self-reported normative data from Dutch children with NH. Concerning the subscales, the School QoL scores among children with HL were clinically lower compared to children with NH at Time 2. Parent-reported and self-reported QoL scores of children with HL were not significantly and clinically different at Time 2, except for the Physical QoL, which was reported more positively by the parents.

\subsection{Changes in QoL over time and the relation with risk and protective factors}

Changes in QoL over time were analyzed using the parent-reported data of 62 children with HL and a linear mixed model with Time as the time-dependent variable. A positive coefficient of time indicates an increase in QoL over time and a negative coefficient indicates a decrease in QoL over time (Table 3). The parent-reported Total QoL of children with HL decreased significantly from Time 1 to Time 2, but this was not clinically different as the absolute value of 4 was not exceeded [14]. When considering the different subscales, no clinical differences were observed in parent-reported Physical QoL and Emotional QoL between Time 1 and Time 2, but the scores on the School QoL and Social QoL subscales had significantly and clinically declined at Time 2 . 


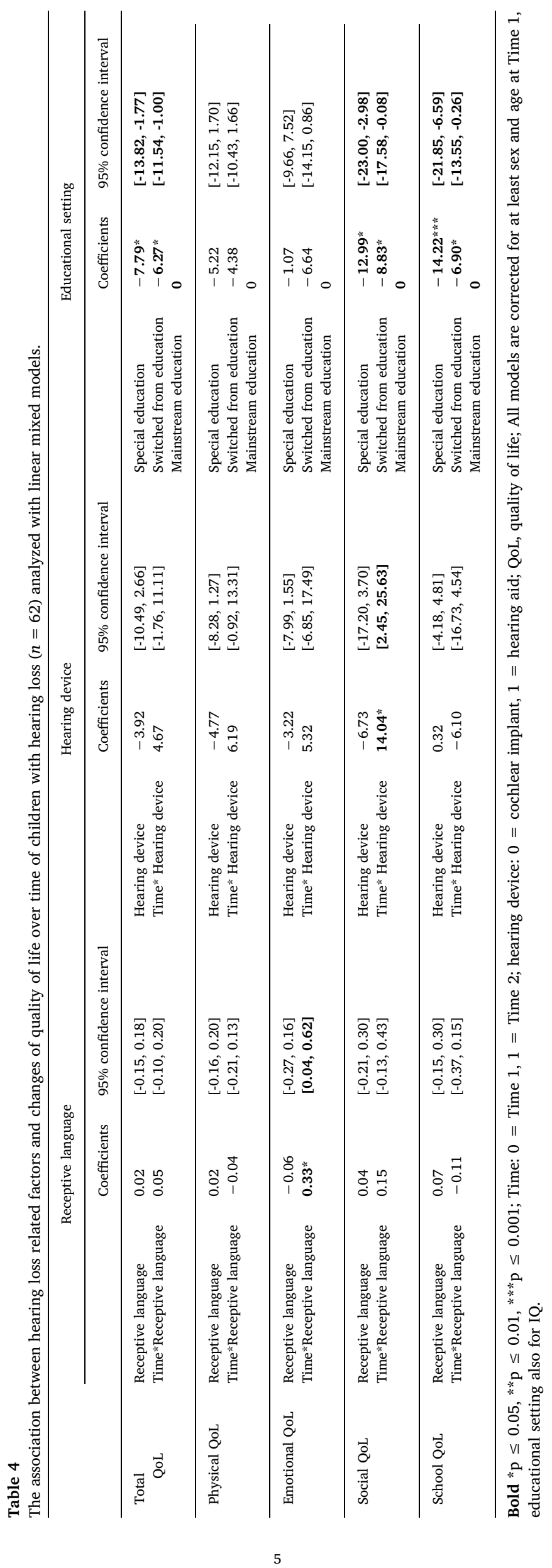




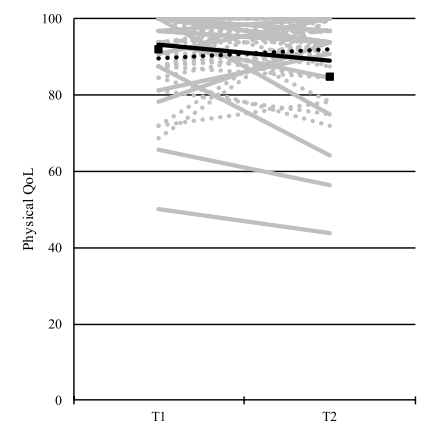

A

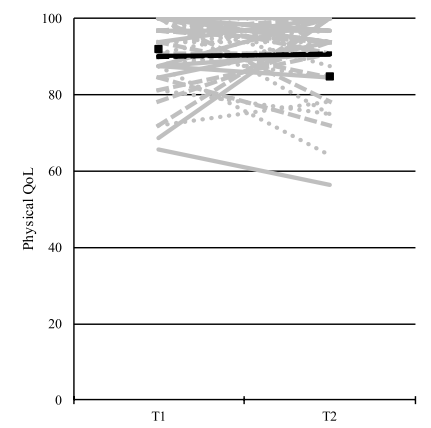

B

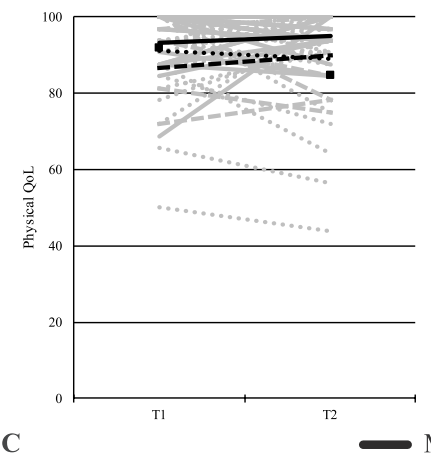

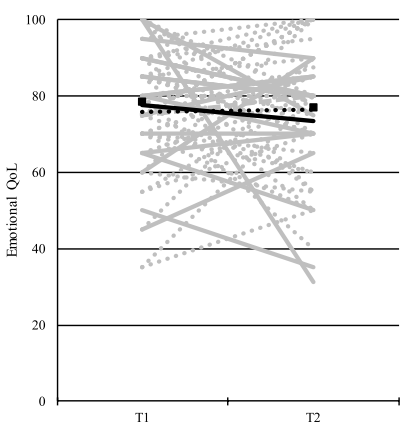

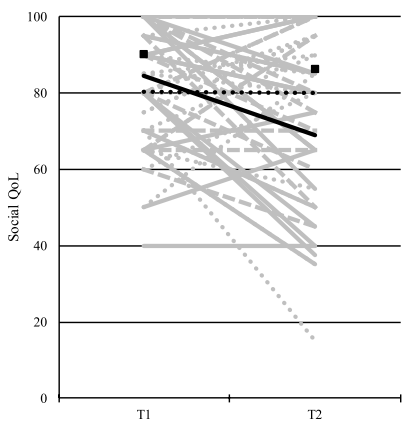

$\longrightarrow$ Cochlear implant $\bullet$. Hearing aid $\square$ Normative data
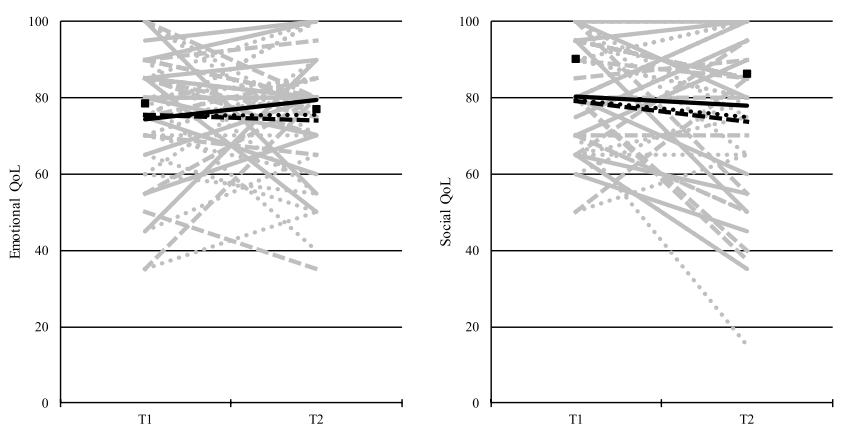

Receptive language $\longrightarrow 100 \bullet 85$ - 100 Normative data
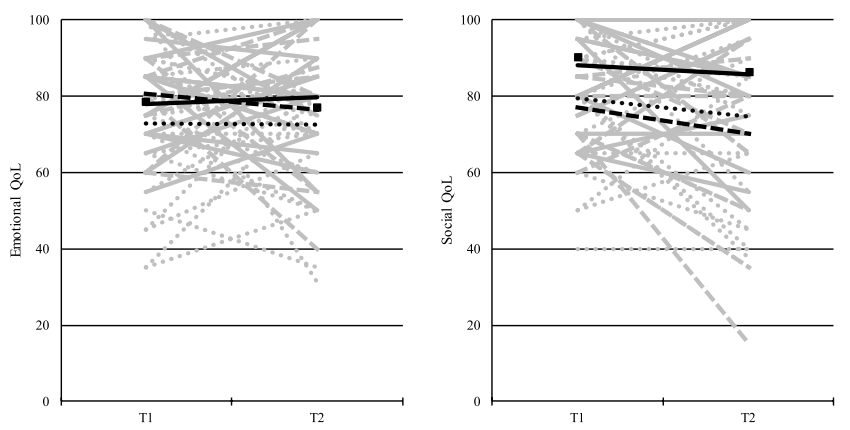
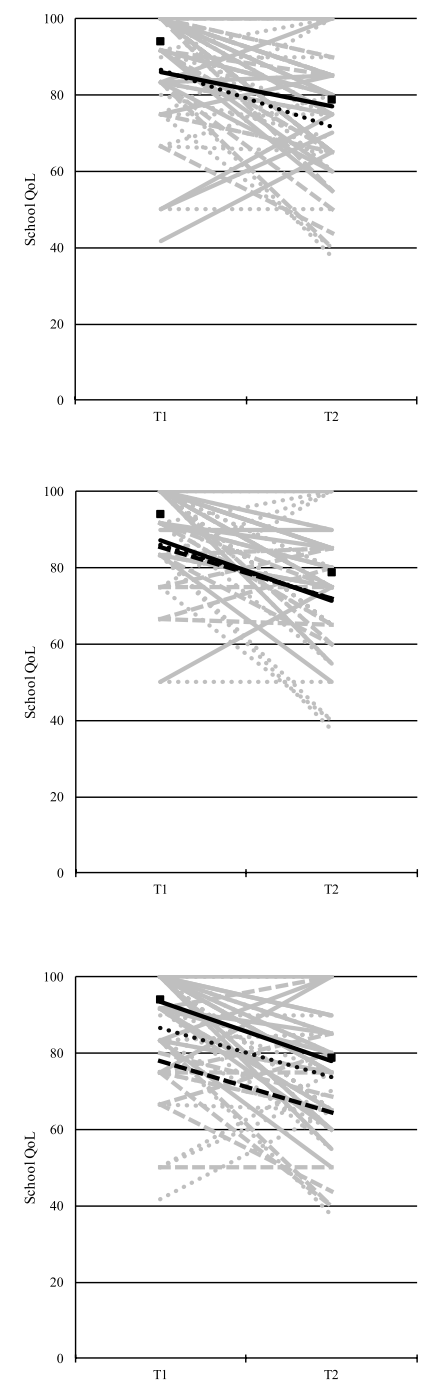

Mainstream $\bullet$. Switched from special to mainstream - - Special $\mathbf{n}$ Normative data

Fig. 1. Changes in the quality of life (QoL) over time of children with HL as reported by their parents $(n=62)$. Individual trajectories are in grey and group differences are plotted in black.

Note. Normative data $=$ Time 1 parent-reported data and Time 2 self-reported data of Dutch children with normal hearing [44,45]. A. Children with cochlear implants showed a clinical decrease in their Social QoL at the second time point, while children with hearing aids had similar Social QoL levels at both time points. No significant difference was found between children with cochlear implants and hearing aids in the other subscales of QoL.

B. Children with HL with adequate receptive language skills (e.g. 100) at age 4 showed a significant increase in their Emotional QoL over time which was not clinically different ( $>4$ points). When receptive language skills were below average (e.g. 80), the Emotional QoL decreased slightly over time. Receptive language skills did not influence the other subscales of QoL.

C. At both time points, children with HL who attended special education $(n=24.2 \%)$ and who switched from special to mainstream education $(n=46.8 \%)$ had a clinically lower Social QoL and School QoL than children with HL in mainstream education $(n=29.0 \%)$. There were no differences between these educational groups in the Physical and Emotional domain.

Notably, the decrease in parent-reported Social QoL was found only in children with CIs (Fig. 1A and Table 4), while children with HAs had similar parent-reported Social QoL outcomes at both time points. Posthoc analyses showed that $75 \%$ of children with CIs (12 of 16 children), but only $37 \%$ of children with HAs (17 of 46 children), had switched from special to mainstream education $(p<0.05)$. Changes in parentreported Total QoL, Physical QoL, Social QoL, and School QoL were not influenced by language or degree of HL. Only parent-reported Emotional QoL was influenced by receptive language (Fig. 1B and Table 4). Children with HL with average receptive language skills (100) at Time 1 had significantly but not clinically higher Emotional QoL at Time 2 (Fig. 1B).

\subsection{Level of QoL differs according to sex and type of education}

To appraise whether QoL of children with HL had changed after 7 years, linear mixed models were used with parent-report data. Based on these parents' reports, sex and the educational setting of children with HL influenced the level of QoL of these children at both time points. When controlled for age and time, linear mixed models showed that boys had a higher Total QoL and Social QoL than girls at both 4 and 11 years of age (coefficient of sex (boys $=1$ girls $=0$ ) for Total $\mathrm{QoL}=5.88,[0.93,10.83], p<0.05$; coefficient of $\operatorname{sex}$ (boys $=1$ girls $=0$ ) for Social QoL $=13.27,[5.31,21.22], p<0.001)$. When corrected for sex, age, IQ, and time, linear mixed models revealed that children who attended special education at one or at both time points had significantly and clinically lower Total QoL, School QoL, and Social QoL than children in mainstream education (Fig. 1C and Table 4). 
Children with HL in mainstream education had similar levels of School QoL and Social QoL to children with NH at both time points.

\section{Discussion}

This longitudinal study examined how type of hearing device and type of education were associated with changes in the QoL of children with HL over a 7-year period. We used the PedsQL ${ }^{\mathrm{TM}}$ questionnaire, which includes assessments of Physical, Emotional, Social, and School functioning. The outcomes of this study confirmed that the Emotional QoL and Physical QoL of 4- and 11-year-old children with HL were similar to the QoL of their peers with NH. The Social QoL and School QoL of children with HL in mainstream education were also on par with these measures in children with NH. However, compared to children with and without HL in mainstream education, children with HL who were in special education or who switched from special to mainstream education had lower levels of Social and School QoL. Regarding changes in the QoL, children with HL who had at least average receptive language skills at 4 years of age had statistically but not clinically improved emotional QoL at 11 years of age. In line with findings in children with $\mathrm{NH}$, School QoL decreased between the ages of 4 and 11 years. Social QoL also declined over time, but only for children with CIs; in contrast, the Social QoL of children with HAs did not differ at both assessment times. These findings were all of clinical importance and can be used to modify and improve personalized care for children with HL by creating a focus on their social interactions and school activities.

\subsection{QoL of children with and without HL}

Our findings confirmed those of the meta-analysis by Roland et al. [14], in that we found that the Emotional QoL and the Physical QoL of children with HL were similar to those of children with $\mathrm{NH}$ at the ages of 4 and 11 years. A novel finding in group differences was the similar level of Social and School QoL of children with HL in mainstream and children with $\mathrm{NH}$ at both ages.

\subsection{Social and School QoL of children with HL in different educational settings}

Children in special education and children who switched from special to mainstream education had lower Social QoL and School QoL than children with HL in mainstream education and children with $\mathrm{NH}$ at both time points. This is in line with previous studies which found that children with HL in special schools, as opposed to children in mainstream schools, have more problems due to their difficulties with language and communication and presumably some additional nonauditory disabilities, all of which may contribute negatively to their QoL [25,26,28,29,57,58].

Almost half of the children with HL in this study had adequate language skills in the range of children with $\mathrm{NH}$, which enabled them to transfer from special to mainstream education. Therefore, this study is the first to investigate the impact of a school transition on the QoL of children with HL. The Social QoL and School QoL of children who switched from special to mainstream education were lower at both time points compared to children with HL in mainstream education. At the first assessment time point, 4-year-old children with HL were in special education and had to catch up due to language and communication delays [8]. It is likely that social interactions and school activities were more challenging at that age $[25,28]$. Seven years later, children with HL who switched to mainstream education may have struggled with the demands of a faster teaching pace and/or with the less favorable acoustics of mainstream classrooms [29]. Furthermore, due to the level of (extra) noise, children with HL regularly misperceive information in class and social situations, which can lead to feelings of exclusion [7,9,10,59-61]. These feelings of exclusion might even be enhanced since children with HL in mainstream settings are often the only ones wearing hearing technology in a hearing classroom. This can affect their self-perception, social development, friendships, and eventually their QoL $[33,60,62]$. Based on the results of this study, it is important to consider specific and long-term guidance regarding school activities and social interactions for children with HL who switch from special to mainstream education.

\subsection{Changes in QoL over time}

According to parents, the School QoL and Social QoL of children with HL changed over time. All children with HL experienced a decline in School QoL after 7 years, which is in line with findings among children with $\mathrm{NH}[44,45]$. This decrease may have been related to their developmental stage of adolescence and concomitantly a more demanding educational curriculum for older children, which the children must learn to cope with.

In contrast to our expectations, the receptive and expressive language scores of 4-year-old children with HL did not clinically contribute to the development of QoL. The absence of a clear relation between language skills and QoL in children with HL was also found in other studies on language skills and social emotional functioning [12,63-66]. They found that communication skills and not language skills are more import for social functioning which in turn can affect the wellbeing of children with HL. Language skills such as vocabulary are learned by professionals in schools and are important to develop communication skills $[4,12]$. Yet, the social rules are learned in a more indirect way by observing and communicating with others outside of school or at the playground. Understanding a joke for example requires the understanding behind the vocabulary and relies on the pragmatics within communication. It is therefore more important that children with HL learn to use their language capacities in the right way.

\subsubsection{Children with HAs or CIs}

Except for Social QoL, changes in the QoL of children with CIs did not differ from changes in children with HAs. The parents of children with HAs reported similar Social QoL when their children were 4 and 11 years old, whereas parents of children with CIs reported a decrease in Social QoL after 7 years. This finding should be interpreted with care due to the difference in group size (the $\mathrm{CI}$ group was three times smaller than the HA group) and the difference in degree and etiology of HL between groups. However, three plausible explanations could be suggested for the change in Social QoL over time for children with CIs. First, children with CIs participated in intensive rehabilitation programs in their early years. Such programs gave them access to speech therapists, psychologists, qualified teachers for children with HL, and other professionals. However, for older children with CIs, the frequency of rehabilitation services usually decreases to once a year and children must be more self-reliant which can result in a lower QoL. Second, the decrease in Social QoL could be a consequence of the fact that parents of children with CIs may expect their child to be like children with $\mathrm{NH}$ and social problems in their 4-year-old child may go unnoticed [67]. When the children with CIs are 11 years old, they can express themselves concerning their difficulties with social interactions and parents of children with CIs may be, therefore, more aware of the difficulties. Third, regarding the educational settings of these two groups, $75 \%$ of children with CIs, but just $37 \%$ of children with HAs, switched from special to mainstream education between the two time points. This greater number of children with CIs who switched educational settings may have had more of an impact on their social development than explained previously.

\subsection{Strengths and limitations}

One of the strengths of this study is its longitudinal design. It provides a unique, and valid perspective on QoL changes in children with 
HL over a period of 7 years, from pre-school to pre-adolescence. It would be informative to follow this cohort into adolescence, when the demands of social interactions and school become even greater. This third time point would provide more information regarding causal relationships and could further validate our findings. In addition, children in this study were born in the implementation phase of the Newborn Hearing Screening preventing us from drawing conclusions concerning the age at detection or the age at first amplification and QoL. However, factors like audibility, early access to amplification, and family counseling have been proven to influence language skills in children with HL and should therefore be integrated in future studies when studying QoL in this group [68]. The study had three main limitations. First, the QoL of children with HL was compared to normative QoL data instead of being compared to data from a control group of children with $\mathrm{NH}$. Second, compared to the 4-year-old children who only participated at the first time point, 4-year-old children with HL who participated at both time points had a higher Total QoL as rated by their parents and had mothers with a higher educational degree. These differences together with the response rate of $30.4 \%$ may have potentially led to selection bias. From a statistical point of view, the linear mixed models used address this problem if the missing data is missing "at random", i.e. the reason for missing data can be explained by the covariates in the model. As we have included sex and age in the model, we believe that important sources of bias have been considered. This being said, the possibility of bias cannot be eliminated. Third, this study used a generic health-related QoL questionnaire to compare the QoL of children with and without HL and to examine the development of QoL over time for children with HL. Despite the relative positive findings concerning the generic QoL of the children with HL in our study, children with HL could still have hearing-specific problems and consequently a lower hearing-specific QoL $[18,24,69]$. Future studies should therefore take the development of hearing-specific QoL into account for children with HL.

\section{Conclusion}

In this longitudinal study, the Physical and Emotional QoL levels of children with HL were in line with those of children with $\mathrm{NH}$ at the ages of 4 and 11 years. Half of the children with HL in this study had appropriate language skills, which allowed them to switch from special to mainstream education. However, for good clinical practice, they should receive extra guidance and long-term support for school activities and social interactions. In particular, school-aged children with CIs may need extra guidance for their social functioning. It is our expectation that these findings can be used to improve personalized guidance for children with HL.

\section{Financial support}

The DECIBEL-study was financially supported by the HeinsiusHoubolt Fund, the Willem-Alexander Children's Fund, and the Wieger Wakinoerfund.

\section{Declaration of competing interest}

None.

\section{Appendix A. Supplementary data}

Supplementary data to this article can be found online at https:// doi.org/10.1016/j.ijporl.2019.109701.

\section{References}

[1] A.M.H. Korver, S. Konings, F.W. Dekker, M. Beers, C.C. Wever, J.H.M. Frijns, A.M. Oudesluys-Murphy, For the DECIBEL Collaborative Study Group, Newborn hearing screening vs later hearing screening and developmental outcomes in children with permanent childhood hearing impairment, Jama 304 (2010) 1701-1708, https://doi.org/10.1016/j.yped.2011.06.003.

[2] S. Mehra, R.D. Eavey, D.G. Keamy, The epidemiology of hearing impairment in the United States: newborns, children, and adolescents, Otolaryngol. Neck Surg. 140 (2009) 461-472, https://doi.org/10.1016/j.otohns.2008.12.022.

[3] C.P.B. van der Ploeg, S.M. van der Pal, P.H. Verkerk, Monitoring van de resultaten van de neonatale gehoorscreening uitgevoerd door de jeugdgezondheidszorg van 2008 tot en met 2015, Www.Rivm.Nl, 2015.

[4] M.P. Moeller, J.B. Tomblin, C. Yoshinaga-Itano, C.M. Connor, S. Jerger, Current state of knowledge: language and literacy of children with hearing impairment, Ear Hear. 28 (2007) 740-753, https://doi.org/10.1097/AUD.0b013e318157f07f.

[5] J. Stevenson, J. Kreppner, H. Pimperton, S. Worsfold, C. Kennedy, Emotional and behavioural difficulties in children and adolescents with hearing impairment: a systematic review and meta-analysis, Eur. Child Adolesc. Psychiatry 24 (2015) 477-496, https://doi.org/10.1007/s00787-015-0697-1.

[6] C. Yoshinaga-Itano, From screening to early identification and intervention: discovering predictors to successful outcomes for children with significant hearing loss, J. Deaf Stud. Deaf Educ. 8 (2003) 11-30, https://doi.org/10.1093/deafed/8. 1.11.

[7] A.E. Geers, L.S. Davidson, R.M. Uchanski, J.G. Nicholas, Interdependence of linguistic and indexical speech perception skills in school-age children with early cochlear implantation, Ear Hear. 34 (2013) 562-574, https://doi.org/10.1097/ AUD.0b013e31828d2bd6.

[8] R.W. McCreery, E.A. Walker, M. Spratford, R. Bentler, L. Holte, P. Roush, J. Oleson, J. Van Buren, M.P. Moeller, Longitudinal predictors of aided speech audibility in infants and children, Ear Hear. 36 (2015) 24S-37S, https://doi.org/10.1097/AUD. 0000000000000211.

[9] S. Nittrouer, A. Caldwell-Tarr, E. Tarr, J.H. Lowenstein, C. Rice, A.C. Moberly, Improving speech-in-noise recognition for children with hearing loss: potential effects of language abilities, binaural summation, and head shadow, Int. J. Audiol. 52 (2013) 513-525, https://doi.org/10.3109/14992027.2013.792957.

[10] M. Picard, J.S. Bradley, Revisiting speech interference in Classrooms:Revisando la interferencia en el habla dentro del salón de clases, Int. J. Audiol. 40 (2001) 221-244, https://doi.org/10.3109/00206090109073117.

[11] J. Fellinger, D. Holzinger, R. Pollard, Mental health of deaf people, Lancet 379 (2012) 1037-1044, https://doi.org/10.1016/S0140-6736(11)61143-4.

[12] A.P. Netten, C. Rieffe, S.C.P.M. Theunissen, W. Soede, E. Dirks, A.M.H. Korver, S. Konings, A.M. Oudesluys-Murphy, F.W. Dekker, J.H.M. Frijns, Early identification: language skills and social functioning in deaf and hard of hearing preschool children, Int. J. Pediatr. Otorhinolaryngol. 79 (2015) 2221-2226, https://doi.org/ 10.1016/j.ijporl.2015.10.008.

[13] S.C.P.M. Theunissen, C. Rieffe, A.P. Netten, J.J. Briaire, W. Soede, M. Kouwenberg, J.H.M. Frijns, Self-esteem in hearing-impaired children: the influence of communication, education, and audiological characteristics, PLoS One 9 (2014), https:// doi.org/10.1371/journal.pone.0094521.

[14] L. Roland, C. Fischer, K. Tran, T. Rachakonda, D. Kallogjeri, J.E.C. Lieu, Quality of life in children with hearing impairment: systematic review and meta-analysis, Otolaryngol. Neck Surg. 155 (2016) 208-209, https://doi.org/10.1177/ 0194599816640485.

[15] Ø. Nordvik, P.O. Laugen Heggdal, J. Brännström, F. Vassbotn, A.K. Aarstad, H.J. Aarstad, Generic quality of life in persons with hearing loss: a systematic literature review, BMC Ear Nose Throat Disord. 18 (2018) 1, https://doi.org/10. 1186/s12901-018-0051-6.

[16] H. Liu, H.X. Liu, H.Y. Kang, Z. Gu, S.L. Hong, Evaluation on health-related quality of life in deaf children with cochlear implant in China, Int. J. Pediatr. Otorhinolaryngol. 88 (2016) 136-141, https://doi.org/10.1016/j.ijporl.2016.06. 027.

[17] E.A. Schorr, F.P. Roth, N.A. Fox, Quality of life for children with cochlear implants: perceived benefits and problems and the perception of single words and emotional sounds, J. Speech Lang. Hear. Res. 52 (2009) 141-152, https://doi.org/10.1044/ 1092-4388(2008/07-0213.

[18] J.H. Clark, N. Wang, A.W. Riley, C.M. Carson, R.L. Meserole, F.R. Lin, L.S. Eisenberg, E.A. Tobey, A.L. Quittner, H.W. Francis, J.K. Niparko, Timing of cochlear implantation and parents' global ratings of children's health and development, Otol. Neurotol. 33 (2012) 545-552, https://doi.org/10.1097/MAO. ob013e3182522906.

[19] P. Kushalnagar, M. McKee, S.R. Smith, M. Hopper, D. Kavin, S.R. Atcherson, Conceptual model for quality of life among adults with congenital or early deafness, Disabil. Health J. 7 (2014) 350-355, https://doi.org/10.1016/j.dhjo.2014.04.001.

[20] Whoqol Group, The development of the world health organization quality of life assessment instrument (the WHOQOL), Qual. Life Assess. Int. Perspect, Springer Berlin Heidelberg, Berlin, Heidelberg, 1994, pp. 41-57, , https://doi.org/10.1007/ 978-3-642-79123-9_4.

[21] M. Wake, S. Tobin, B. Cone-Wesson, H.H. Dahl, L. Gillam, L. McCormick, Z. Poulakis, F.W. Rickards, K. Saunders, O.C. Ukoumunne, J. Williams, Slight/mild sensorineural hearing loss in children, Pediatrics 118 (2006) 1842-1851, https:// doi.org/10.1542/peds.2005-3168.

[22] S. Borton, E. Mauze, J. Lieu, Quality of life in children with unilateral hearing loss: a pilot study, Am. J. Audiol. 19 (2010) 61-72, https://doi.org/10.1044/10590889(2010/07-0043 (Quality).

[23] M. Wake, E.K. Hughes, C.M. Collins, Z. Poulakis, Parent-reported health-related quality of life in children with congenital hearing loss: a population study, Ambul. Pediatr. 4 (2004) 411-417, https://doi.org/10.1367/A03-191R.1.

[24] T. Rachakonda, D.B. Jeffe, J.J. Shin, L. Mankarious, R.J. Fanning, M.M. Lesperance, J.E.C. Lieu, Validity, discriminative ability, and reliability of the hearing-related 
quality of life questionnaire for adolescents, The Laryngoscope 124 (2014) 570-578, https://doi.org/10.1002/lary.24336.

[25] B. Schick, A. Skalicky, T. Edwards, P. Kushalnagar, T. Topolski, D. Patrick, School placement and perceived quality of life in youth who are deaf or hard of hearing, J. Deaf Stud. Deaf Educ. 18 (2013) 47-61, https://doi.org/10.1093/deafed/ens039.

[26] S.C.P.M. Theunissen, C. Rieffe, M. Kouwenberg, L.J.I. De Raeve, W. Soede, J.J. Briaire, J.H.M. Frijns, Behavioral problems in school-aged hearing-impaired children: the influence of sociodemographic, linguistic, and medical factors, Eur. Child Adolesc. Psychiatry 23 (2014) 187-196, https://doi.org/10.1007/s00787013-0444-4.

[27] C. Yoshinaga-Itano, Early intervention after universal neonatal hearing screening: impact on outcomes, Ment. Retard. Dev. Disabil. Res. Rev. 9 (2003) 252-266, https://doi.org/10.1002/mrdd.10088.

[28] A. Keilmann, A. Limberger, W.J. Mann, Psychological and physical well-being in hearing-impaired children, Int. J. Pediatr. Otorhinolaryngol. 71 (2007) 1747-1752, https://doi.org/10.1016/j.ijporl.2007.07.013.

[29] M. Hintermair, Health-related quality of life and classroom participation of deaf and hard-of-hearing students in general schools, J. Deaf Stud. Deaf Educ. 16 (2011) 254-271, https://doi.org/10.1093/deafed/enq045.

[30] M. Chorozoglou, M. Mahon, H. Pimperton, S. Worsfold, C.R. Kennedy, Societal costs of permanent childhood hearing loss at teen age: a cross-sectional cohort follow-up study of universal newborn hearing screening, BMJ Paediatr. Open 2 (2018) e000228, , https://doi.org/10.1136/bmjpo-2017-000228.

[31] L. De Raeve, Education and rehabilitation of deaf children with cochlear implants: a multidisciplinary task, Cochlear Implants Int. 11 (Suppl 1) (2010) 7-14, https:// doi.org/10.1179/146701010X12671178390717.

[32] E. Marlatt, The evolution of the education of deaf and hard of hearing children into speech-language pathology, educational audiology, and special education, Am. Ann. Deaf 158 (2014) 484-485, https://doi.org/10.1353/aad.2014.0001.

[33] Y.H. Xie, M. Potměšil, B. Peters, Children who are deaf or hard of hearing in inclusive educational settings: a literature review on interactions with peers, J. Deaf Stud. Deaf Educ. 19 (2014) 423-437, https://doi.org/10.1093/deafed/enu017.

[34] L. Sontag, Passend onderwijs in de praktijk Ervaringen met innovatieve, (2006).

[35] C. Bisegger, B. Cloetta, U. von Bisegger, T. Abel, U. Ravens-Sieberer, Health-related quality of life: gender differences in childhood and adolescence, SozialPräventivmed. SPM 50 (2005) 281-291, https://doi.org/10.1007/s00038-0054094-2.

[36] T. Meade, E. Dowswell, Adolescents' health-related quality of life (HRQoL) changes over time: a three year longitudinal study, Health Qual. Life Outcomes 14 (2016) 1-8, https://doi.org/10.1186/s12955-016-0415-9.

[37] V. Looi, Z.Z. Lee, J.H.Y. Loo, Hearing-related quality of life outcomes for Singaporean children using hearing aids or cochlear implants, Eur. Ann. Otorhinolaryngol. Head Neck Dis. 133 (2016) S25-S30, https://doi.org/10.1016/j anorl.2016.01.011.

[38] L. Anmyr, M. Olsson, K. Larson, A. Freijd, Children with hearing impairment - living with cochlear implants or hearing aids, Int. J. Pediatr. Otorhinolaryngol. 75 (2011) 844-849, https://doi.org/10.1016/j.ijporl.2011.03.023.

[39] L. Smith-Olinde, S.D. Grosse, F. Olinde, P.F. Martin, J.M. Tilford, Health state preference scores for children with permanent childhood hearing loss: a comparative analysis of the QWB and HUI3, Qual. Life Res. 17 (2008) 943-953, https://doi. org/10.1007/s11136-008-9358-x.

[40] D.L. Patrick, T.C. Edwards, A.M. Skalicky, B. Schick, T.D. Topolski, P. Kushalnagar, M. Leng, A.M. O'Neill-Kemp, K.S. Sie, Validation of a quality-of-life measure for deaf or hard of hearing youth, Otolaryngol. Head Neck Surg. 145 (2011) 137-145, https://doi.org/10.1177/0194599810397604.

[41] A.P. Netten, C. Rieffe, W. Soede, E. Dirks, A.M.H. Korver, S. Konings, J.J. Briaire, A.M. Oudesluys-Murphy, F.W. Dekker, J.H.M. Frijns, DECIBEL Collaborative study group, Can you hear what I think? Theory of mind in young children with moderate hearing loss, Ear Hear. 38 (2017) 588-597, https://doi.org/10.1097/AUD. 0000000000000427

[42] J.W. Varni, M. Seid, C.A. Rode, The PedsQL: measurement model for the pediatric quality of life inventory, Med. Care 37 (1999) 126-139 http://www.ncbi.nlm.nih. gov/pubmed/10024117.

[43] J.W. Varni, C.A. Limbers, The pediatric quality of life inventory: measuring pediatric health-related quality of life from the perspective of children and their parents, Pediatr. Clin. N. Am. 56 (2009) 843-863, https://doi.org/10.1016/j.pcl. 2009.05.016.

[44] S.A. Schepers, H.A. van Oers, H. Maurice-Stam, J. Huisman, C.M. Verhaak, M.A. Grootenhuis, L. Haverman, Health related quality of life in Dutch infants, toddlers, and young children, Health Qual. Life Outcomes 15 (2017) 81, https:// doi.org/10.1186/s12955-017-0654-4.

[45] V. Engelen, M.M. Haentjens, S.B. Detmar, H.M. Koopman, M.A. Grootenhuis, Health related quality of life of Dutch children: psychometric properties of the PedsQL in The Netherlands, BMC Pediatr. 9 (2009) 68, https://doi.org/10.1186/1471-24319-68.

[46] J.W. Varni, M. Seid, P.S. Kurtin, PedsQL 4.0: reliability and validity of the Pediatric
Quality of Life Inventory version 4.0 generic core scales in healthy and patient populations, Med. Care 39 (2001) 800-12 http://www.ncbi.nlm.nih.gov/pubmed/ 11468499.

[47] M. van Eldik, Meten van taalbegrip en taalproductie: Constructie, normering en validering van de Reynell test voor taalbegrip en de Schlichting test voor taalproductie, (1998).

[48] W. Kort, M. Schittekatte, E. Compaan, CELF-4-NL: Clinical Evaluation of Language Fundamentals, Amsterdam Pearson Assess. Inf. B.V., 2008.

[49] E. Semel, E. Wiig, W. Secord, CELF: Clinical Evaluation of Language fundamentals-revised., San Antonio, TX, (1987).

[50] P. Tellegen, J. Laros, The construction and validation of a nonverbal test of intelligence: the revision of the Snijders-Oomen tests, Eur. J. Psychol. Assess. 9 (1993) $147-157$.

[51] P. Kort, M. Schittekatte, E.L. Compaan, M. Bosmans, N. Bleichrodt, G. Vermeir, W.C.M. Resing, Verhaeghe, WISC-III NL. Guide. Dutch Version, Psychol. Corp. London, 2002.

[52] D. Wechsler, Manual for the Wechsler Intelligence Scale for Children, third ed., Psychol. Corp., San Antonio, 1991.

[53] U. Neisser, G. Boodoo, T.J. Bouchard, A. Wade Boykin, N. Brody, S.J. Ceci, D.F. Halpern, J.C. Loehlin, R. Perloff, R.J. Sternberg, S. Urbina, Intelligence: knowns and unknowns, Am. Psychol. 51 (1996) 77-101.

[54] A.P. Netten, F.W. Dekker, C. Rieffe, W. Soede, J.J. Briaire, J.H.M. Frijns, Missing data in the field of otorhinolaryngology and head \& neck surgery, Ear Hear. 38 (2017) 1-6, https://doi.org/10.1097/AUD.0000000000000346.

[55] S. van Buuren, Flexible Imputation of Missing Data, Chapman and Hall/CRC, New York, 2012https://www.taylorfrancis.com/books/9781439868256.

[56] J.A.C. Sterne, I.R. White, J.B. Carlin, M. Spratt, P. Royston, M.G. Kenward, A.M. Wood, J.R. Carpenter, Multiple imputation for missing data in epidemiological and clinical research: potential and pitfalls, BMJ 338 (2009), https://doi.org/10. 1136/bmj.b2393 b2393-b2393.

[57] N. Wakil, E.M. Fitzpatrick, J. Olds, D. Schramm, J. Whittingham, Long-term outcome after cochlear implantation in children with additional developmental disabilities, Int. J. Audiol. 53 (2014) 587-594, https://doi.org/10.3109/14992027 2014.905716.

[58] A. Zaidman-zait, D. Curle, J.R. Jamieson, R. Chia, F.K. Kozak, Health-related quality of life among young children with cochlear implants and developmental disabilities, Ear Hear. (2017) 1-10, https://doi.org/10.1097/AUD.0000000000000410.

[59] R.W. Mccreery, E.A. Walker, M. Spratford, J. Oleson, R. Bentler, L. Holte, P. Roush, Speech recognition and parent-ratings from auditory development questionnaires in children who are hard of hearing HHS public access, Ear Hear. 36 (2015) 60-75, https://doi.org/10.1097/AUD.0000000000000213.

[60] C. Rieffe, E. Broekhof, A. Eichengreen, M. Kouwenberg, G. Veiga, B.M.S. da Silva, A. van der Laan, J.H.M. Frijns, Friendship and emotion control in pre-adolescents with or without hearing loss, J. Deaf Stud. Deaf Educ. 23 (2018) 209-218, https:// doi.org/10.1093/deafed/eny012.

[61] N. Wolters, H.E.T. Knoors, A.H.N. Cillessen, L. Verhoeven, Predicting acceptance and popularity in early adolescence as a function of hearing status, gender, and educational setting, Res. Dev. Disabil. 32 (2011) 2553-2565, https://doi.org/10. 1016/j.ridd.2011.07.003.

[62] I.W. Leigh, I.W. Leigh, Inclusive education and personal development, J. Deaf Stud Deaf Educ. 4 (1999) 236-245, https://doi.org/10.1093/deafed/4.3.236.

[63] G. Constantinescu-Sharpe, R.L. Phillips, A. Davis, D. Dornan, A. Hogan, Social inclusion for children with hearing loss in listening and spoken Language early intervention: an exploratory study, BMC Pediatr. 17 (2017) 1-11, https://doi.org/10 1186/s12887-017-0823-y.

[64] A.P. Netten, C. Rieffe, L. Ketelaar, W. Soede, K.D. Gadow, J.H.M. Frijns, Terrible twos or early signs of psychopathology? Developmental patterns in early identified preschoolers with cochlear implants compared with hearing controls, Ear Hear. 39 (2018) 495-502, https://doi.org/10.1097/AUD.0000000000000500.

[65] S.M. Horwitz, J.R. Irwin, M.J. Brigs-Gowan, J.M. Bosson Heenan, J. Mendoza, A.S. Carter, Language delay in a community cohort of young children, J. Am. Acad. Child Adolesc. Psychiatry 42 (2003) 932-940, https://doi.org/10.1097/01.CHI. 0000046889.27264.5E

[66] J.H. Beitchmen, R. Nair, M. Clegg, B. Ferguson, P.G. Patel, Prevalence of psychiatric disorders in children with speech and language disorders, J. Am. Acad. Child Psychiatry 25 (1986) 528-535, https://doi.org/10.1016/S0002-7138(10)60013-1.

[67] A. Zaidman-Zait, T. Most, Cochlear implants in children with hearing loss: maternal expectations and impact on the family, Volta. Rev. 105 (2005) 129-150 http:// psycnet.apa.org/psycinfo/2006-11015-002.

[68] J.B. Tomblin, M. Harrison, S.E. Ambrose, E.A. Walker, J.J. Oleson, M.P. Moeller, Language outcomes in young children with mild to severe hearing loss, Ear Hear. (2015) 76-91, https://doi.org/10.1097/AUD.0000000000000219.

[69] A.M. Umansky, D.B. Jeffe, J.E.C. Lieu, The HEAR-QL: quality of life questionnaire for children with hearing loss, J. Am. Acad. Audiol. 22 (2011) 644-653, https://doi. org/10.3766/jaaa.22.10.3.The. 